\title{
POLÍTICA E EDUCAÇÃO: OBSERVAÇÕES ACERCA DE INESSA ARMAND - FEMINISTA, REVOLUCIONÁRIA E EDUCADORA.
}

\author{
POLÍTICA Y EDUCACIÓN: OBSERVACIONES SOBRE INESSA ARMAND - FEMINISTA, \\ REVOLUCIONARIA Y EDUCADORA.
}

\section{POLICY AND EDUCATION: OBSERVATIONS ABOUT INESSA ARMAND - FEMINIST, REVOLUTIONARY AND EDUCATOR.}

DOI: http://dx.doi.org/10.9771/gmed.v12i1.36883

\author{
Anita Helena Schlesener \\ Gisele Masson ${ }^{2}$
}

\begin{abstract}
Resumo: O propósito deste artigo é tecer algumas considerações acerca da contribuição de Inessa Armand ao processo de Revolução Russa de 1917 como militante política, feminista e educadora. Para tanto, apresentamos algumas notas biográficas acentuando que, apesar de ter sido uma figura de primeiro plano no Partido Bolchevique, tanto antes da Revolução atuando na clandestinidade contra o czarismo quanto depois de 1917, na organização do movimento das mulheres, são poucas as fontes que abordam sua vida e seu trabalho de militante. Em seguida, fazemos observações acerca do trabalho educativo por ela desenvolvido, tanto como diretora do Zhenotdel, Departamento das Mulheres do Comitê Central do Partido Bolchevique. Fazemos observações sobre a experiência escolar de Paris, junto a Nadezhda Krupskaja na criação de uma escola alternativa para jovens militantes. Acentuamos a contribuição de muitas mulheres na organização e direção do processo educativo soviético, que lutaram bravamente para que a Revolução de Outubro de 1917 se efetivasse e cujos nomes ficaram no anonimato.
\end{abstract}

Palavras-chave: Política, educação, feminismo revolucionário, Inessa Armand.

Resumen: El propósito de este artículo es hacer algunas consideraciones sobre la contribución de Inessa Armand al proceso de la Revolución Rusa de 1917 como activista política, feminista y educadora. Con este fin, presentamos algunas notas biográficas que enfatizan que, aunque fue una figura destacada en el Partido Bolchevique, tanto antes de la Revolución actuando bajo tierra contra el zarismo como después de 1917, en la organización del movimiento de mujeres, hay pocas fuentes que abordar su vida y su trabajo como militante. A continuación, hacemos observaciones sobre el trabajo educativo desarrollado por ella, tanto como directora de Zhenotdel, Departamento de Mujeres del Comité Central del Partido Bolchevique. Comentamos sobre la experiencia escolar de París, junto con Nadezhda Krupskaja en la creación de una escuela alternativa para jóvenes activistas. Hacemos hincapié en la contribución de muchas mujeres en la organización y dirección del proceso educativo soviético, que lucharon valientemente por la revolución de octubre de 1917 y cuyos nombres permanecieron en el anonimato.

Palabras clave: política, educación, feminismo revolucionario, Inessa Armand.

Abstract: The purpose of this article is to make some considerations about Inessa Armand's contribution to the 1917 Russian Revolution process as a political activist, feminist and educator. Therefore, we present some biographical notes emphasizing that, although he was a leading figure in the Bolshevik Party, both before the Revolution acting underground against Tsarism and after 1917, in the organization of the women's movement, there are few sources that address his life and his work as a militant. Next, we make observations about the educational work developed by her, both as director of Zhenotdel, the Party's Department for Work Among Women. We make observations about the Paris school experience, together with Nadezhda Krupskaja in the creation of an alternative school for young activists. We emphasize the contribution of many women in organizing and directing the Soviet educational process, who fought bravely for the October 1917 Revolution to take place and whose names remained anonymous.

Keywords: Politics, education, revolutionary feminism, Inessa Armand. 


\section{Introdução:}

Acontece sempre assim: para que um fato nos interesse e nos comova, torne-se uma parte de nossa vida interior, é necessário que aconteça próximo de nós [...] (GRAMSCI, 2015, p. 193)

Grandes Revoluções marcaram a vida e as transformações das sociedades desde que a humanidade se reconhece como tal. Nelas, as figuras centrais sempre foram as mulheres, principalmente na retaguarda dos movimentos, dando sustentação aos homens nas frentes de luta e arcando com o trabalho necessário para a continuidade da vida da sociedade. Figuras anônimas na história das revoluções e das guerras, as mulheres sempre desempenharam um papel fundamental de sustentação do trabalho e da ação dos homens nas lutas. Nas revoluções de Fevereiro e de Outubro de 1917 as mulheres atuaram clandestinamente na organização dos movimentos tanto quanto os homens, porém, poucas tiveram seus nomes e suas corajosas ações reconhecidos.

Cabe ainda acentuar que a Revolução de Outubro de 1917, que redefiniu os caminhos da história mundial, foi praticamente ignorada pela história ocidental e isso se entende se considerarmos, com Walter Benjamin (1985, p. 225), que "todos os que até hoje venceram participam do cortejo triunfal, em que os dominadores de hoje espezinham os corpos dos que estão prostrados no chão". Em outras palavras, a narrativa histórica é feita pelos vencedores que, na batalha ideológica que o registro da memória representa, suas vitórias são a expressão da verdade universal e o vencido precisa ser esquecido.

Mas existem dois fatores que precisam ser acentuados para esclarecer a legitimidade do movimento de Outubro de 1917: foi a primeira vez que a classe trabalhadora tomou efetivamente o poder com o propósito de controlar o seu trabalho e instaurar um novo projeto de sociedade; foi um marco na história do século XX, que motivou a classe trabalhadora do mundo inteiro a lutar pelo seu sonho de um novo mundo possível, sem ter que seguir a corrente do desenvolvimento e do progresso capitalista, como afirmavam os líderes deterministas da social democracia.

As condições históricas da grande revolução operária foram magnificamente narradas por Trotsky em A História da Revolução Russa. É preciso acentuar que a Rússia tinha características específicas que serviram para mobilizar a sociedade: um Estado autoritário, cuja estrutura administrativa e burocrática se alicerçava na aristocracia agrária, com abertura para o capital estrangeiro que trazia investimentos para a nascente indústria, com uma burguesia nacional fragilizada e premida por esta estrutura. A guerra com o Japão (1904-1905) enfraqueceu ainda mais essa estrutura econômica e política arcaica; a derrota nessa guerra aprofundou a situação de fome e miséria dos trabalhadores rurais e urbanos, situação insustentável que eclodiu na insurreição de 1905, com o massacre determinado pelo Czar e que ficou conhecido como “domingo sangrento". Trotsky (1978, p. 1) salienta que a "revolução de 1905 surgiu diretamente da guerra russo-japonesa, assim como a revolução de 1917 foi a consequência direta do grande massacre imperialista". Essa compreensão, porém, se esclarecer 'a "luz dos acontecimentos de 1917”.

A pressão popular aumentou depois da insurreição de 1905 levando o Czar a convocar a Duma, uma espécie de parlamento consultivo, que não alterava a estrutura do Estado autoritário e absolutista. Nos anos seguintes os conflitos sociais se agravaram gerando novas greves e insurreições que levaram o Czar a 
abdicar em fevereiro de 1917, abrindo-se o caminho para a grande revolução, que se estendeu de fevereiro a outubro de 1917: inicialmente instaura-se um governo provisório nascido de alianças entre as forças políticas em presença, forças conflitantes, que representavam os grupos burgueses e socialistas, que não conseguiram evitar a formação de um poder paralelo dos trabalhadores que, unidos aos soldados, organizavam os soviets. Entre fevereiro e outubro se organizou a revolução, com a ascensão política dos bolcheviques, que conseguiram assumir a liderança do movimento, liderança que se deveu em grande medida ao esforço e disciplina organizativa de Lenin.

No contexto da Revolução Russa, a emancipação das mulheres foi sempre reconhecida como fundamental para a implementação de um novo projeto de sociedade. No entanto, como salienta Fairfax (1999, p. 3), a “imagem popular da Revolução Russa é a de uma revolução feita por homens”. Na verdade, muitas mulheres participaram ativamente do movimento e, precisamente por isso, "foram forçadas a romper seus laços familiares". Algumas, como "Vera Karavaikovka, abandonaram todo contato com os pais" a partir do momento que se juntaram ao movimento e passaram a atuar clandestinamente. "Outras, como Inessa Armand, Aleksandra Kollontaj e Evgenia Bosch, deixaram os maridos, que não eram revolucionários". Precisaram de muita coragem e determinação para se lançarem no movimento operário e feminista, num mundo dominado pelos homens também no campo marxista. Mulheres que tiveram que estudar muito para demonstrar sua capacidade e tornar as relações mais igualitárias, inclusive no interior do movimento socialista. Outras simpatizavam com o marxismo, como a professora Ekaterina Shalaginova, que dizia ter sido atraída pelos marxistas, mas não tinha coragem de pedir que eles alguma proteção quanto ao trabalho (FAIRFAX, 1999, p. 11). As mulheres da classe trabalhadora tinham que enfrentar situações mais difíceis em relação ao trabalho antes da Revolução e precisavam de muita coragem ante o medo de ficar sem trabalho. Muitas, porém, se engajaram completamente na luta.

Mulheres organizaram a imprensa, dirigiram círculos de trabalhadores, escreveram artigos, editaram jornais, davam palestras e ensinavam a disparar armas. Orientavam as líderes de comitês partidários e em vários momentos desempenharam importantes funções de liderança central. (FAIRFAX 1999, p. 12)

A participação das mulheres na luta contra o czarismo na Rússia tem sido identificada por pesquisadores desde os levantes de 1905, gerados pela profunda crise econômica e social que se expressava na desigualdade social, na fome e na miséria que atingia as classes populares. Como ressalta Murphy (2017, p. 137), "não foi coincidência que a greve mais importante da história mundial tenha começado com mulheres do setor têxtil em Petrogrado no dia Internacional da Mulher de 1917’. O trabalho nas fábricas, o frio, a fome, a luta diária para sustentar a família enquanto os maridos lutavam na guerra, foram as condições empíricas que motivaram o movimento. A multidão de mulheres, nas ruas, incitava os indecisos a assumirem a greve, agitavam bandeiras vermelhas e cantavam canções revolucionárias. (MURPHY, 2017, p. 139).

Essa consciência política, entretanto, não nasceu do vazio, mas implicou um longo trabalho de formação para transformar a concepção de mundo tradicional e retirar as mulheres das condições de 
submissão e subalternidade a que estavam reduzidas no contexto de uma família tradicional e de um Estado autoritário.

Cabe acentuar que uma grande parcela da população feminina vivia no meio rural, enfrentava a dura labuta da terra, além do trabalho doméstico. Nessas comunidades, "o poder e a importância de cada membro estão muito mais relacionados com a participação produtiva do que com a existência de um arcabouço legal de garantias individuais". Ainda neste contexto, o "caráter coletivo da comuna" e a forma de propriedade da terra asseguravam "uma relação entre gêneros de maior equilibrio se comparadas ‘s relações puramente burguesas em que a propriedade individual, os direitos individuais", se sobrepunham aos coletivos (MANZANO, 2017, p. 145).

O objetivo deste artigo é tecer algumas considerações acerca da contribuição de Inessa Armand ao processo de Revolução Russa de 1917 como militante política, feminista e educadora. Para tanto, foram consultados basicamente escritos de: Ralph Carter Elwood, Kathy Fairfax, e Annalisa Paradiso e Wladimir Lenin, além dos artigos de Kevin Murphy, Sofia Manzano e Marisa Bittar / Amarilio Ferreira Jr., além de um panfleto escrito por Inessa Armand e publicado no Boletim Comunista no. 17 de 08 de julho de 1920.

Dessa perspectiva, apresentamos algumas notas biográficas acentuando que, apesar de ter sido uma figura de primeiro plano no Partido Bolchevique, tanto antes da Revolução atuando na clandestinidade contra o czarismo quanto depois de 1917, na organização do movimento das mulheres, são poucas as fontes que abordam sua vida e seu trabalho de militante.

Em seguida, fazemos observações acerca do trabalho educativo por ela desenvolvido, tanto como diretora do Departamento das Mulheres do Comitê Central do Partido Bolchevique quanto do seu trabalho em Paris, junto a Nadezhda Krupskaja na criação de uma escola alternativa para jovens militantes. Entendese aqui a educação em seu sentido amplo enquanto formação para a vida e criação de uma nova sociedade, ou seja, na sua dimensão política, porque a luta de classes se efetiva no cotidiano social e escolar como confronto entre projetos de sociedade.

\section{Notas sobre a vida e a ação política de Inessa Armand:}

El poder soviético ha sido el primero en crear las condiciones en la que la mujer podrá coronar, finalmente, la obra de su proia emancipación. (ARMAND, 1920, p. 12)

Uma das figuras mais impressionantes do movimento revolucionário, uma das poucas mulheres a tomar uma posição de frente no movimento de resistência ao czar, foi Inessa Armand. Conforme Elwood (1993, p. 120), “antes da Revolução Russa de 1917, Inessa desempenhou um papel importante, apesar de muitas vezes auxiliar, no subterrâneo do movimento bolchevique". Depois da revolução, ela assumiu a direção da Seção Feminina do Partido Comunista, com uma atuação muito importante na elaboração do Jornal das trabalhadoras.

Nascida em Paris em 1875, faleceu em 1920, vitima da cólera. Casou-se aos 18 anos com Alexander Armand, um rico industrial têxtil russo, com quem conviveu 10 anos e teve quatro filhos. Mais tarde, o quinto filho nasceu de seu relacionamento com Wladimir Armand, irmão do marido. Pouco se sabe 
sobre ela, cujas biografias, como ressalta Paradiso (1997, p. 857), "sob vários aspectos de sua vida, foram muito reticentes". Sua atuação e participação no movimento revolucionário foi, de certa forma, ocultada pelo Partido Bolchevique em função do seu relacionamento afetivo com Lenin. Somente a partir de 1992 sua biografia passou a ser conhecida com a publicação do artigo cientifico de Elwood, com base em extensa consulta documental e a biografia de Bardawil, um "ensaio histórico em formato de ficção, com base em testemunhos e material inédito (cartas, diários, postais, etc.)" (PARADISO, 1997, p. 857).

Como ressalta Fairfax (1999, p. 26), "ela acreditava que era direito de todas as mulheres buscar a auto-realização e uma vida socialmente útil". Em carta de 1908 para o marido, escrevia: "O marxismo não foi para mim um entusiasmo da juventude, mas a conclusão de uma longa evolução da direita para a esquerda" (ARMAND, apud FAIRFAX, 1999, p. 26).

Da sua militância política sabe-se muito pouco: ingressou no Partido Social Democrata Russo em 1903 e, a partir de sua atuação foi presa em 1907 pelo governo imperial e condenada a dois anos de prisão no norte da Rússia. Conseguiu escapar da prisão em 1908, dirigindo-se a Paris, onde encontrou Lenin e outros exilados bolcheviques. Retornou para a Rússia em 1912, com o objetivo de participar ativamente da organização do movimento operário e da campanha bolchevique para eleger seus apoiadores para a Duma. Dois meses depois, ela foi novamente presa, apenas para ser libertada sob fiança (paga pelo marido) em março de 1913. Mais uma vez deixou a Rússia ilegalmente e foi morar na França com Vladimir Lenin e Nadezhda Krupskaja.

Depois de Outubro de 1917, sua atuação foi marcante no Partido comunista, organizando o movimento das mulheres e no debate das questões da emancipação feminina. Personalidade forte e independente, "dotada de espírito de iniciativa autônomo e frequentemente muito crítico", foi dirigente do Zhenotdel (Departamento de Mulheres Trabalhadoras e Mulheres Camponesas do Partido), instituído em 1919 com o objetivo de organizar o movimento feminino russo. O obscurecimento de sua imagem e biografia, conforme Eldwood, deveu-se a "razões privadas e políticas: a historiografia stalinista entendia retaliar e isolar uma imagem perfeita de Lenin" como homem inteiramente dedicado à revolução e “castamente unido à revolucionária Krupskaja” (PARADISO, 1997, p. 860).

Paradiso (1997, p. 861) salienta ainda que não foi somente Inessa Armand a "sofrer o ostracismo historiográfico entre as primeiras bolcheviques". Apenas depois da queda do stalinismo é que foram reabilitadas, a partir da década de 1970, as figuras de Aleksandra Kollontaj e de Nadezhda Krupskaja. A figura de Inessa, porém, permanece imprecisa: poucas referências à sua "personalidade cultural e política, ao seu trabalho interno no Partido" e de sua relevância política; apresentam-na apenas como "uma espécie de secretária inteligente de Lenin", nada mais. Inessa Armand parece "ter sido aprisionada em uma espécie de conspiração do silêncio", para proteger a imagem de Lenin (PARADISO, 1997, p. 865).

Fosse ou não uma "amizade amorosa", diz Paradiso (1997, p. 866), a vida privada não deveria servir para ocultar a sua efetiva ação política, a sua autonomia de pensamento e de ação, de uma mulher de formação burguesa que, com esforço e disciplina, numa "evolução progressiva que, antes do encontro com Lenin", a levou à "descoberta de uma consciência social e, portanto, política, do feminismo ao marxismo" e que a transformou numa educadora. Nos primeiros anos de 1900 atuou em "uma escola para os habitantes 
de Eldigino, no trabalho de recuperação moral e social das prostitutas, na aproximação aos grupos socialdemocratas", participando na Comissão educacional da Sociedade de Moscou para o Aperfeiçoamento das Mulheres, Sociedade para a qual ela foi nomeada presidente em 1900, cargo que ocuparia por mais de três anos (ELWOOD, 1993). Estas atividades a levaram à prisão czarista e ao exílio.

No exílio francês, onde convivia com Lenin e Krupskaja, os três militantes, enquanto moravam em Paris, organizaram durante o verão de 1911, na pequena cidade rural de Longjumeau, $19 \mathrm{~km}$ ao sul de Paris, uma escola para trabalhadores, estudantes interessados ou os exilados. A pequena distância de Paris possibilitava a vinda dos alunos de trem ou de bicicleta, como uma das medidas de segurança que Lenin estabeleceu para proteger a escola. "O centro das operações da escola ficava no número dezessete - uma casa, com um pátio e uma loja de metalurgia, arrendada pelo verão por Inessa Armand”. Os estudantes, em torno de vinte, tinham participação na gestão da escola: cinco deles participaram da "Comissão Escolar, com poderes para decidir sobre cursos e palestras com a concordância do recém-formado Colégio de Estudantes". Os demais alunos se dividiam nos cargos de Tesoureiro presidente, secretário, bibliotecário; o diretor e mestre da escola era efetivamente Lenin (ELWOOD, 1966, p. 384).

Tudo era muito bem organizado, articulado com muita disciplina: Lenin iniciava o dia escolar as 8:30 h. E, após a sua aula, Inessa Armand frequentemente conduzia o seu seminário, deixando Lenin livre para voltar a Paris para cuidar das questões do partido. Depois do almoço em uma sala comum, dois outros professores davam palestras em torno de duas horas. Perto do final do verão, faziam-se aulas também à noite, a fim de cumprir o currículo planejado (ELWOOD, 1966, p. 386). Os domingos eram de folga, para pedalar e ir nadar no rio Sena.

Tratava-se de uma experiência inovadora, com palestras dadas por Lenin, Armand, Zinoviev e outros bolcheviques, com o objetivo de estudar teoria política e história, e pensar os caminhos da nova escola socialista, na verdade "um embrião da Universidade comunista do futuro" (ELWOOD, 1966, p. 382).

Inessa Armand teve uma participação ativa na organização da escola de Longjumeau, também dando palestras e conduzindo seminários. "Nenhuma outra mulher, nem mesmo Krupskaja [...], lecionou em Longjumeau e nenhum outro palestrante contou com Lenin em todas as suas palestras" (ELWOOD, 1966, p. 388). Sem a sua formação cultural e autonomia política "não se explicaria a confiança e a estima com a qual Lenin lhe confiou os cursos de economia política" na escola do Partido, "seminários dos quais ele próprio participou". Nem se poderia entender todas as missões delicadas ou difíceis e perigosas que Lenin lhe atribuiu, até a presidência do Zhenotdel, que ela dirigiu até a sua morte (PARADISO, 1997, p. 867).

\section{Notas sobre Inessa Armand como educadora:}

Em Longjumeau, "à noite, os aldeões ouviam os alunos cantarem cancões de seus países de origem e Lenin, uma vez, dirigiu um coro conjunto de a 'Marselhesa”.' (ELWOOD, 1966, p. 383)

A emancipação feminina precisa acontecer no processo de construção revolucionária e isso implica inserir as mulheres na vida pública: 
Enquanto as mulheres não forem chamadas a participar livremente da vida pública em geral, cumprindo também as obrigações de um serviço cívico permanente e universal, não pode haver socialismo, nem sequer democracia integral e durável. As funções de polícia, como as de assistência a doentes e crianças abandonadas, o controle da alimentação, etc., não podem, em geral, ter uma execução satisfatória enquanto as mulheres não hajam obtido a igualdade perante os homens, não sólido nominal, mas efetiva. (LENIN, 1979, p. 101)

Entendia-se que o tema da emancipação feminina tinha condicionado o papel da mulher na família, ou seja, articulava-se não apenas a mudanças estruturais econômicas e políticas como base para a participação das mulheres na vida pública, mas também a transformações culturais e ideológicas, que implicavam numa mudança radical nas formas de educação. Acentuou-se o compromisso do Estado com mudanças no sistema jurídico para garantir legalmente a transformação da família, com leis sobre o divórcio e o aborto, reconhecendo os direitos da mulher e sua importância na vida política e econômica da sociedade. Instituiu-se uma rede de proteção e assistência à maternidade e à infância, a educação mista nas escolas com a reformulação de todo o processo educativo voltado à compreensão do coletivo como novo modo de vida e de inserção social.

Nas condições econômicas e sociais da sociedade russa de 1905-1917, esse consistia num dos maiores desafios a enfrentar e que tinha como pressuposto superar todas as formas de desigualdade econômica, social e cultural existentes. Reconhecia-se que a população camponesa era, na sua maioria e principalmente as mulheres, analfabeta e seria necessário tomar medidas educacionais efetivas para introduzi-las na vida política ativa. Inessa Armand compreendeu desde o início de sua atuação no Zhenotdel que o grande limite a superar no processo de organização das mulheres era o analfabetismo, de modo que uma das ações mais importantes foi a criação de uma escola de alfabetização, com o objetivo de instrução e de formação de uma consciência política.

Alfabetizar significava esclarecer para as mulheres operárias e camponesas que não pertenciam ao Partido, que a revolução lhes havia aberto o acesso a direitos até então inexistentes, ou seja, a alfabetização tinha uma dimensão política de formação da consciência e de compreensão da importância de colaborar com o coletivo para a construção de uma nova ordem social. Esse trabalho era acompanhado pela redação semanal de um Boletim divulgado pelo Zhenotdel e também por um jornal editado mensalmente, o Kommunistka, com redação compartilhada por Inessa Armand e Aleksandra Kollontaj.

O trabalho redacional era acompanhado por um processo de formação continuada por meio de palestras e seminários regionais e nacionais, trabalho permanente de panfletagem e esclarecimentos sobre a nova realidade a ser construída; criar, assim, a possibilidade de participação ampla e envolvimento do maior número de mulheres na vida política. Estas atividades eram acompanhadas pela criação de um sistema de creches, cozinhas comunitárias e lavanderias, tudo no sentido emergencial de gerar as condições de participação efetiva das mulheres no movimento social e político.

Em um de seus escritos, possivelmente de formação continuada, Inessa Armand (1920, p. 12) acentuava que o "poder soviético foi o primeiro a criar as condições nas quais as mulheres podem finalmente completar o trabalho de sua própria emancipação". Até então, operárias e camponesas foram escravas da família, não apenas porque submetidas ao poder do marido, mas também porque a fábrica não as libera 
“das preocupações da maternidade e da economia doméstica”, o que significa dupla jornada de trabalho. A “Constituição soviética deu `as mulheres todos os direitos políticos e cívicos”: direito ao voto, a escolherem e serem escolhidas, a ocuparem cargos públicos. Descreve ainda todas as políticas sociais de proteção da infância e da mulher a fim de garantir esta emancipação. Retoma o conteúdo das conferências e congressos até então realizados: a importância da economia coletiva, substituindo a economia doméstica, base para uma união livre entre camaradas, cidadãos iguais do novo Estado operário.

Durante o período em que dirigiu o Departamento das Mulheres, organizou assembleias reunindo as delegadas regionais orientando sobre as novas legislações, as determinações das conferências a respeito da prostituição, da maternidade, do casamento livre, sempre esclarecendo o caminho no sentido da emancipação feminina. Avalia os resultados alcançados depois de um ano de atuação frente ao Departamento, a magnífica atuação das mulheres na sua "capacidade de organização e de trabalho". (ARMAND, 1920, p. 15)

Tinha a clareza de que a luta seria longa, porque exigia a transformação de um modo de pensar e de viver, a transformação radical dos costumes, mais que da própria lei ou do direito burguês com sua igualdade meramente formal. Formar novos hábitos e costumes implicava um longo processo educativo para arrancar as "raízes da opressão e da desigualdade das mulheres de maneira mais profunda, como não tinha ousado ainda nenhum partido ou revolução no mundo” (LENIN, 1979, p. 106).

Era preciso instaurar um processo de formação continuada no qual o processo gradual de apropriação da linguagem escrita fosse acompanhada da formação política no movimento contínuo da luta de classes. E se a formação da subjetividade feminina se constitui em desafio permanente na sociedade capitalista, na luta pela construção deu uma nova ordem social ela se torna imensurável; mas é necessário contar com a nova realidade de pertencimento de classe que veio à tona a partir da pressão das lutas e das greves enfrentadas e que são a base para a formação de um novo costume, um novo modo de vida. Inessa Armand, Aleksandra Kollontaj e Nadezhda Krupskaja se empenharam juntas a enfrentar esse desafio no Departamento das Mulheres do Partido bolchevique.

Inessa Armand, juntamente com Nadezhda Krupskaja, já havia participado de uma experiência de uma escola para o proletariado na sua estadia francesa, com a expectativa de vivenciar uma nova pedagogia voltada para a educação em uma sociedade fundada no coletivo e na interlocução horizontal entre mestres e alunos. Uma prática que visava a esclarecer os caminhos de transformação da escola pública em escola do trabalho, que fosse uma escola de formação integral. Depois da Revolução de Outubro, empenhou-se ao lado de Krupskaja pela erradicação do analfabetismo na Rússia Soviética, principalmente junto ‘as mulheres trabalhadoras e camponesas.

Os primeiros anos da revolução foram intensos na dedicação ao processo educativo. Como salientam Bittar e Ferreira Jr. (2015, p. 437), foram “anos que valeram séculos”.

Anos que valeram séculos. Talvez esta seja a frase que melhor expresse o esforço educacional da Rússia Soviética no difícil contexto para erradicar o analfabetismo: construir um sistema educacional de escolas públicas, expandir o saber científico, as artes e, ainda, instituir a educação tecnológica e física, um programa gigantesco diante das condições materiais do país. (BITTAR e FERREIRA Jr., 2015, p. 437) 
Um grande desafio que implicava superar uma concepção de mundo tradicional, patriarcal, autoritária, que caracterizava o senso comum numa sociedade na qual os indivíduos não conheciam seus direitos, apenas lutavam por pão e terra. Os revolucionários tiveram que fazer esforços inauditos para recuperar a economia com implantação de novas indústrias e a transformação do sistema agrário, o que exigia adesão coletiva consciente e participativa. As transformações radicais no âmbito da educação eram fundamentais para que esse projeto desse certo. Fazia-se necessário reformular todo o sistema educacional e seus projetos pedagógicos:

Era necessário criar novos programas que proporcionassem o conhecimento das leis básicas do desenvolvimento das ciências da natureza e da sociedade humana e, portanto, gerar uma nova racionalidade que fosse capaz de estabelecer as múltiplas e complexas conexões existentes entre os próprios homens e a natureza nos marcos da sociedade socialista. (BITTAR e FERREIRA Jr., 2015, p. 439)

Bittar e Ferreira Jr. (2015, p. 453) concluem que "no primeiro período revolucionário da Rússia Soviética, apesar do contexto histórico desfavorável ao processo de consolidação do poder bolchevique", esse período foi caracterizado "pelo forte entusiasmo construtivo e a vontade de profunda renovação das instituições".

Conforme Forster (2019, p. 64), o "trabalho do Zhenotdel e das mulheres que lutaram para alcançar esta conquista ainda está em diálogo" neste início de século XXI, com "uma das demandas atuais do feminismo", com grande "impulso na América Latina, no movimento 'maré verde' que surgiu na Argentina" em defesa do aborto legal, seguro e gratuito e que usa como símbolo um lenço verde amarrado no pulso. O lema desse movimento é: "Educação sexual para decidir, anticoncepcionais para não abortar, aborto legal para não morrer".

As lutas femininas, em todos os tempos, implicam enfrentar a questão da educação, tanto na sua forma institucional quanto como formação para a vida, o que vai muito além da simples formação para o trabalho, mas implica a consciência clara de que precisamos formar seres autônomos e capazes de decidir sobre seu próprio destino.

Inessa Armand, assim como Aleksandra Kollontaj e Nadehzda Krupskaja foram grandes educadoras, cada uma na sua área de atuação e que, juntamente com milhares de outras mulheres que a história deixou incógnitas, deram todo o seu esforço e empenho para que a Revolução Russa se concretizasse como emancipação de todos os seres humanos. O conhecimento dos fatos e os debates que podem ser ainda despertados mostram que essa história permanece inconclusa.

\section{Para concluir:}

O debate em torno da condição feminina tem um campo fértil no movimento revolucionário russo, principalmente no período que se estendeu de 1905 a 1917. A ação das mulheres foi fundamental tanto nas greves quanto no próprio movimento em curso, mobilizando trabalhadores e soldados para a luta que elas sentiam não poder mais ser adiada. Entendemos que o verdadeiro feminismo tem que ser revolucionário. E na atividade de Inessa Armand, que abandonou os privilégios da vida burguesa para 
mergulhar na luta política pela revolução comunista, a militância teve uma dimensão pedagógica, entendendo-se educação no sentido amplo de formação para a vida social. Dedicou-se principalmente ao processo de alfabetização e formação das mulheres. Com uma primorosa formação cultural (dominava quatro idiomas), teve uma participação ativa ao lado de Lenin, inclusive representando-o em eventos internacionais. "Promoveu a disseminação da educação e do treinamento técnico das mulheres"; em 1900, solicitou permissão para abrir uma escola dominical oferecendo educação básica aos trabalhadores (ELWOOD, 1993, p. 28).

A sua participação ativa na organização e ensino na escola de Longjumeau, onde ajudou a selecionar, treinar e formar um grupo de estudantes trabalhadores vinculados ao partido, foi decisiva para as suas atividades no Zhenotdel, principalmente defendendo os direitos sociais das mulheres que, para ela implicavam fundamentalmente no acesso a uma educação básica alfabetizadora e política.

Cabe acentuar ainda que, além de algumas militantes que atuaram efetivamente na organização e direção do processo educativo soviético, muitas mulheres, cujos nomes ficaram no anonimato, lutaram bravamente para que a Revolução de Outubro de 1917 se efetivasse. A história não pode esquecer o legado feminista na luta revolucionária e na construção da nova ordem social e política.

A luta de classes, algumas vezes latente mas sempre em pauta nos mostra que a educação tem uma importância política fundamental na formação e organização de coletivos. Revoluções podem voltar a acontecer porque transformações radicais continuam sendo necessárias.

\section{Referências:}

ARMAND, Inessa. La obrera en la Rusia Sovietica. Bulletin Communiste. N. 17, 08/07/1920, p. 12-15. Disponível em: https://www.marxists.org/espanol/armand/la-obrera-sovietica.pdf BENJAMIN, Walter. Obras Escolhidas: Magia e Técnica, Arte e Política. São Paulo: Brasiliense, 1985. BITTAR, Marisa e FERREIRA Jr., Amarilio. Ativismo pedagógico e princípios da escola do trabalho nos primeiros tempos da educação soviética. In: Revista Brasileira de Educação. V. 20, n. 61, p. 433-456, abril/jun. 2015.

CLEMENTS, B. Inessa Armand: Revolutionary and Feminist. By R. C. Elwood. New York: Cambridge University Press, 1992. xi, 304 p. Index. Plates. \$49.95, hard bound. Slavic Review, vol. 52, no 2, p. 366367, 1993.

ELWOOD, Ralph Carter. Inessa Armand: Revolutionary and Feminist. Cambridge and New York:

Cambridge University Press, 1993. Disponível em: https://search.proquest.com/openview/bb187ad8284fe068b19b6afa0febfac1/1?pqorigsite $=$ gscholar\&cbl=1817079. Acesso em: 03/05/2020.

ELWOOD, Ralph Carter. Lenin and the Social Democratic Schools for Underground Party Workers, 1909-1911. In: Political Science Quartely. V. 81, n 3, p. 370-391, set. 1966. Disponível em: https://www.jstor.org/stable/2147640?readnow $=1 \&$ refreqid=excelsior $\% 3 \mathrm{~A} 427$ aafad6cc2d409dc2631857282dcdc\&seq=13\#page_scan_tab_contents. Acesso em: 16/05/2020.

FAIRFAX, Kathy. Comrades in Arms: Bolsevik Women in the Russian Revolution. Resistance Books, 1999. Disponível em:

https://books.google.com.br/books?id=BHEf7EBiY4EC\&printsec $=$ frontcover\&hl $=\mathrm{it} \# \mathrm{v}=$ onepage\&q\&f =false. Acessado em: 03/05/2020. 
FORSTER, Sara Lua Gonzalez. Nadheda Krupskaja y las mujeres socialistas en la Revolucion Rusa, una Mirada feminista. Revista Entre Diversidades, v. 6, n. 2, p. 43-73, jul./dez, 2019.

GRAMSCI, Antonio. Armênia. Scritti Giovanili (1914-1918). Torino: Einaudi, 1975, p. 29-30. Traduzido em: SCHLESENER, Ana Paula. Antonio Gramsci e a Revolução Socialista: primeiros escritos. In:

Cadernos de Pesquisa: Pensamento Educacional. V. 10, n. 24, p. 191-205, 2015.

LENIN, Wladimir Ilich. As tarefas do proletariado em nossa revolução. In: MARX; ENGELS; LENIN. Sobre a Mulher. São Paulo: Global Ed., 1979.

MANZANO, Sofia. A mulher na Revolução Russa. Lutas Sociais, São Paulo, v. 21, n. 38, p. 136-149, 2017.

MURPHY, Kevin. A historia da Revolução Russa de fevereiro de 1917. Revista Outubro, n. 28, p. 135149, abril, 2017.

PARADISO, Annalisa. Inessa Armand: Rivoluzionaria e femminista. In: Studi Storici. Anno 38, n. 3, p. 857-868, jul-set,1997.

TROTSKY, Leon. A história da revolução russa. Rio de Janeiro: Paz e Terra, 1980.

TROTSKY, Leon. A revolução de 1905. São Paulo: Global Ed. 1978.

Acesso em 05/05/2020.

\section{Notas:}

1 Doutora em História, Pós-doutoradoemeducação (UNICAMP). Docente de filosofia política e estetica da UFPR de 1976 a 2005; Docente do Mestrado e Doutorado em Educação da UTP. Líder do Grupo Estado e Políticas Educacionais http://dgp.cnpq.br/dgp/espelhogrupo/32819 Lattes: http://lattes.cnpq.br/9617648836292663 Orcid: https://orcid.org/00000002-5185-2604 Email: anitahelena1917@gmail.com

2 Doutorado em Educacao na UFS-SC Pos-doutorado em Educacao na UFSC- SC Currículo na Plataforma Lattes: http://lattes.cnpq.br/7544786717624293 Orcid: https://orcid.org/0000-0002-9799-5950 Email: gimasson@,uol.com.br 